\title{
CD81-induced behavioural changes during chronic cocaine administration: in vivo gene delivery with regulatable lentivirus
}

\author{
Amine Bahi, ${ }^{1}$ Frederic Boyer, ${ }^{1}$ Tal Kafri ${ }^{2}$ and Jean-Luc Dreyer ${ }^{1}$ \\ ${ }^{1}$ Institute of Biochemistry, University of Fribourg, Rue du Musée 5, CH-1700 Fribourg, Switzerland \\ ${ }^{2}$ Gene Therapy Center and the Department of Microbiology and Immunology, University of North Carolina at Chapel Hill, USA
}

Keywords: behaviour, CD81, cocaine, drugs of abuse, lentivirus, in vivo gene transfer

\begin{abstract}
CD81, a tetraspanin transmembrane protein involved in cell adhesion, is up-regulated in the mesolimbic dopaminergic pathway $24 \mathrm{~h}$ following acute administration of high doses of cocaine [Brenz-Verca et al., (2001) Mol. Cell. Neurosci., 17, 303-316]. Further evidence consecutive with this observation and based on microarray analysis are presented here. In addition, a regulatable lentivirus was developed bearing the rat $C D 81$ gene under the control of a tetracycline inducible system. This lentivirus vector was stereotaxically injected into the ventral tegmental area (VTA) of two groups of animals, one fed water (expressing CD81) and the other Doxycycline solution (which down-regulates CD81 expression) and locomotor activity after chronic cocaine administration (10 mg/kg daily) was monitored. After 2 weeks, the groups were inverted, animals receiving water were placed on Doxycycline and the second group was placed on water. In all cases highly a significant increase (3.2-fold) in locomotor activity was observed in animals expressing CD81 in the VTA vs. animals placed on Doxycycline. Similar studies where CD81 was delivered into the nucleus accumbens (NAcc) resulted in significantly higher effects (30\%), in accordance with microarray data and our previous reports, yielding a 4.2-fold increase in locomotor activity. No change was observed under similar conditions in control animals, which were injected a regulatable lentivirus expressing GFP. These findings suggest that CD81 expression in the mesolimbic dopaminergic pathway contributes to behavioural changes associated with cocaine sensitization. This study provides a powerful approach for evaluating a gene function in vivo in a single animal under various paradigms, even on gene candidates, which display small changes of expression.
\end{abstract}

\section{Introduction}

Drug addiction is a behavioural and neuropsychiatric disorder related to aberrant brain function and resulting into a loss of control over drugtaking or into compulsive drug-seeking, despite noxious consequences (Nestler, 2000). Understanding the molecular basis of drug addiction is a central challenge in the field and encompasses two major areas of enquiry. One of these is the identification of molecular candidates that partly determines susceptibility to addiction. The other is the use of animal models to investigate the role of specific genes in mediating the development of addiction.

Because addiction, like most other psychiatric disorders is a complex trait, identifying genes that contribute to risk for addiction and assessing their biological function are difficult tasks. In a molecular screening, aimed at identifying such molecular cues, we described CD81, a cell surface protein from the tetraspanin family (Hemler, 2001), as a potential candidate, as it is up-regulated in the nucleus accumbens (NAcc) upon cocaine treatment (Brenz-Verca et al., 1998; Brenz-Verca et al., 2001; Michna et al., 2001; Michna et al., 2002). CD81 is expressed in almost all cell types (Levy et al., 1998; Meacker, 2003; Takeda et al., 2003), but in the brain, it is expressed by neurons in the mesolimbic dopaminergic pathway and the galanin pathway

Correspondence: Dr Jean-Luc Dreyer, as above.

E-mail: jean-luc.dreyer@unifr.ch

Received 5 November 2003, revised 7 January 2004, accepted 12 January 2004 within hypothalamic nuclei (Brenz-Verca et al., 2001). It is also found in glial cells (Sullivan \& Geisert, 1998), and is involved in reactive gliosis (Irwin \& Geisert, 1993), anti-CD81 causing changes in astrocyte morphology (Geisert et al., 1996). CD81 is up-regulated during early postnatal development, at the time of glial birth and neuronal maturation, providing evidence for a role of tetraspanins in brain plasticity. More recent studies found CD81 associated with the melanocortin receptor MC4R in the hypothalamus, elevated expression in obese yellow mice leading to altered neuronal function of MC4R (Lamar et al., 2003).

In this study we confirm further our finding that CD81 is upregulated in the brain-reward pathway after cocaine treatment. To characterize the behavioural changes associated with the expression of CD81 upon drug administration in vivo, we have developed a strong system based on a novel lentiviral vector in which the CD81 cDNA was expressed under the control of a tetracycline inducible promoter. Injecting the newly developed vector into specific brain regions (the NAcc and the VTA) conferred the ability to switch gene expression on/off and evaluate in the very same animal how such in vivo modulation affects its drug-related behaviour. We show that local overexpression of CD81 in the VTA or in the NAcc leads to a 3.2-4.2fold increase in functional activity, which can be reversed by switching off local gene expression. This approach may be very useful in resolving a major challenge in the field, namely to understand how the many genes implicated in this disorder interact to yield as complex a phenotype as addiction. 


\section{Materials and methods}

\section{Microarray preparation and analysis}

\section{Drug treatment}

All animal experiments were carried out in accordance with the guidelines and regulations for Animal Experimentation, BAG, Bern, Switzerland. Animals used for microarray studies were treated as follows: 225-250 g, male Wistar rats (BRL, Fillingsdorf, Switzerland) were injected i.p. with $30 \mathrm{mg} / \mathrm{kg}$ cocaine-HCl (Sigma Chemical Co.) every $2 \mathrm{~h}$ for four injections. Control animals received $0.9 \%$ saline injections under the same schedule. The rats were killed by decapitation $24 \mathrm{~h}$ after the last injection and the brain areas were dissected out and used for total RNA isolation.

\section{Microarray fabrication}

Microarray fabrication was performed according to published methods (Shalon et al., 1996). Briefly, PCR products were arrayed onto silylated microscope slides (CEL Associates, Houston, TX) by using a high precision gridding robot (GeneMachines, San Carlos, CA) equipped with four printing tips (TeleChem International, San Jose, CA). After printing, silylated slides were allowed to dry, and unbound DNA was removed with $0.2 \%$ SDS and double-distilled $\mathrm{H}_{2} \mathrm{O}$; covalently bound DNA was denatured for $2 \mathrm{~min}$ in boiling water. Free aldehydes were reduced by soaking slides for $5 \mathrm{~min}$ in $68 \mathrm{mM}$ sodium borohydride (dissolved in PBS containing 25\% ethanol). Several washing steps were performed with $0.2 \%$ SDS and double-distilled $\mathrm{H}_{2} \mathrm{O}$; then slides were dried by centrifugation at $500 \times \boldsymbol{g}$ for $5 \mathrm{~min}$ and stored at room temperature for further hybridizations.

\section{RNA extraction}

Total RNA was isolated from different brain regions of naïve and cocaine-treated animals $(n=3)$ using TRIzol reagent (Invitrogen \#15596-026). Briefly, $1 \mathrm{~mL}$ of TRIzol was added to $75 \mathrm{mg}$ of tissue, homogenized with a glass homogenizer, vortexed for $30 \mathrm{~s}$ and incubated at room temperature for $5 \mathrm{~min}$. Residual protein was removed by the addition of $0.2 \mathrm{~mL}$ of chloroform, mixing for $30 \mathrm{~s}$, incubation at room temperature for $3 \mathrm{~min}$, and centrifugation for $15 \mathrm{~min}$ at $12000 \times \mathbf{g}$ and $4{ }^{\circ} \mathrm{C}$. The aqueous phase was precipitated with $0.5 \mathrm{~mL}$ of isopropanol by mixing for $15 \mathrm{~s}$, incubation for $10 \mathrm{~min}$ at room temperature, and centrifugation for $10 \mathrm{~min}$ at $12000 \times \boldsymbol{g}$ and $4{ }^{\circ} \mathrm{C}$. The resulting RNA pellet was washed with $1 \mathrm{~mL}$ of $75 \%$ ethanol and centrifuged for $5 \mathrm{~min}$ at $7500 \times \boldsymbol{g}$ and $4{ }^{\circ} \mathrm{C}$. The RNA pellet was air-dried, resuspended in $0.1 \mathrm{~mL}$ of DEPC-treated water, incubated at $60{ }^{\circ} \mathrm{C}$ for $10 \mathrm{~min}$ and stored at $-80^{\circ} \mathrm{C}$.

\section{RNA amplification}

This was performed according to Kacharmina et al. (1999). First strand synthesis was performed in $0.2 \mathrm{~mL}$ RNAse-free PCR tubes as follows: $2 \mu \mathrm{g}$ of total RNA was added to $9 \mu \mathrm{L}$ of $0.6 \mathrm{M}$ trehalose in DEPC water and $1 \mu \mathrm{g}$ Eberwine oligo-dT/T7 primer (5'-AAACGACGGCCAGTGAATTGTAATACGACTCACTATAGGCGCT15-3'). These components were mixed well by pipetting and heated at $65^{\circ} \mathrm{C}$ for $10 \mathrm{~min}$, then kept on ice. Four microlitres of $5 \times$ first strand buffer (Invitrogen) was added to the mixture, followed by $2 \mu \mathrm{L} 0.1 \mathrm{M}$ dithiothreitol, $10 \mathrm{U}$ RNAsin (Invitrogen \#15518-012), $1 \mu \mathrm{L} 10 \mathrm{mM}$ dNTP mix (Promega \#U1240), $1 \mu \mathrm{L}$ linear acrylamide $(0.1 \mathrm{mg} / \mathrm{mL}), 1 \mu \mathrm{L} 200 \mathrm{U} / \mu \mathrm{L}$ Superscript II RNaseH-reverse transcriptase (Invitrogen \#18064-014). The mixture was incubated in a thermocycler at $37^{\circ} \mathrm{C}, 5 \mathrm{~min} ; 45^{\circ} \mathrm{C}, 5 \mathrm{~min}$; then 25 cycles alternating between $60^{\circ} \mathrm{C}, 2 \mathrm{~min}$ and $55^{\circ} \mathrm{C}, 2 \mathrm{~min}$. Tubes were kept on ice, while adding the second strand components. Second strand synthesis was followed by adding $106 \mu \mathrm{L}$ DEPC water, $15 \mu \mathrm{L}$ second strand buffer [200 mM Tris pH 6.9, $900 \mathrm{mM} \mathrm{KCl,} 46 \mathrm{mM}$
$\mathrm{MgCl}_{2}, 1.5 \mathrm{mM}$ nicotine adenine dinucleotide (Calbiochem \#481915), $\left.100 \mathrm{mM}\left(\mathrm{NH}_{4}\right)_{2} \mathrm{SO}_{4}\right)$ ], $3 \mu \mathrm{L} 10 \mathrm{mM}$ dNTP mix (Promega \#U1240), 10 U E. coli DNA ligase (NEB \#205 L), 30 U E. coli DNA polymerase I-holoenzyme (NEB \#209 L), 2 U RNaseH (Invitrogen \#18021071). The mixture was incubated at $16^{\circ} \mathrm{C}$ for $4 \mathrm{~h}$. The reaction was stopped by the addition of $7.5 \mu \mathrm{L} 1 \mathrm{M} \mathrm{NaOH}: 2 \mathrm{mM}$ EDTA and incubation at $65^{\circ} \mathrm{C}$ for $10 \mathrm{~min}$. The dsDNA was extracted once with phenol: chloroform: isoamyl-alcohol $(25: 24: 1)$. One hundred and fifty microlitres of organics were added directly to PCR tubes, mixed and centrifuged for $5 \mathrm{~min}$ at $15000 \times \boldsymbol{g}$ at room temperature. The aqueous phase was transferred to RNase free $1.5 \mathrm{~mL}$ Eppendorf tubes and DNA was precipitated with $70 \mu \mathrm{L}$ of $7.5 \mathrm{M}$ ammonium acetate (in DEPC-water, 0.2 micron filtered) and $1 \mathrm{~mL}$ absolute ethanol $\left(-20{ }^{\circ} \mathrm{C}\right)$. Tubes were vortexed and centrifuged immediately for $20 \mathrm{~min}$ at $15000 \times \boldsymbol{g}$ at room temperature. The pellet was washed once with $100 \mu \mathrm{L}$ absolute ethanol and resuspended in $10 \mu \mathrm{L}$ of DEPC- water. In vitro transcription was then performed with the Ambion T7 Megascript Kit (\#1334), according to the manufacturer's protocol.

\section{Probe preparation and hybridization}

Each aRNA sample (one from saline control sample and one from cocaine-treated sample) was reverse-transcribed in the presence of Cy3-dCTP (saline-treated samples) or Cy5-dCTP (cocaine-treated samples) (Amersham Pharmacia Biotech, Switzerland \#PA53021 and \#PA55021). Each reaction was performed in a $30-\mu \mathrm{L}$ volume containing $2 \mu \mathrm{g}$ of aRNA, $2 \mu \mathrm{g}$ of oligo(dT) $21-\mathrm{mer}, 500 \mu \mathrm{M}$ each of dATP, dGTP, and dTTP, $200 \mu \mathrm{M}$ dCTP, $100 \mu \mathrm{M}$ Cy3-dCTP or Cy5-dCTP, 30 units of RNase inhibitor, $10 \mathrm{~mm}$ dithiothreitol, and 400 units of SuperScriptII reverse transcriptase (Invitrogen \#15508013 ) in SuperScript buffer. After incubation at $42{ }^{\circ} \mathrm{C}$ for $3 \mathrm{~h}$, the sample tubes containing $\mathrm{Cy} 3$ and $\mathrm{Cy} 5$ labelling were pooled and treated with $2.65 \mu \mathrm{L}$ of $25 \mathrm{~mm}$ EDTA and $3.3 \mu \mathrm{L}$ of $1 \mathrm{M} \mathrm{NaOH}$ for $10 \mathrm{~min}$ at $65^{\circ} \mathrm{C}$ to degrade the RNA. After the addition of $3.3 \mu \mathrm{L}$ of $1 \mathrm{M} \mathrm{HCl}$ and $5 \mu \mathrm{L}$ of $1 \mathrm{M}$ Tris- $\mathrm{HCl}, \mathrm{pH} 6.8$, labelled ssDNA was precipitated with 0.1 volume of $3 \mathrm{M}$ sodium acetate and two volumes of ethanol, and the pellet was washed with $80 \%$ ethanol, dried, and resuspended in $10 \mu \mathrm{L}$ of hybridization solution containing $3 \times \mathrm{SSC}$, $0.2 \%$ SDS, and $0.02 \%$ yeast tRNA (Invitrogen \#15401-011). Probes were purified by Millipore (Volketswil, Switzerland) Ultrafree-MC filters.

\section{Hybridization reaction and microarray analysis}

Before hybridization, the probe solution was boiled for $1 \mathrm{~min}$ and then rapidly applied to the microarray under a cover slip. Slides were placed in hybridization chambers, and $20 \mu \mathrm{L}$ of $3 \times$ SSC was placed inside each chamber before sealing. Slides were incubated for $14-16 \mathrm{~h}$ in a water bath at $64{ }^{\circ} \mathrm{C}$ and washed sequentially in the following solutions: $2 \times \mathrm{SSC}, 0.1 \%$ SDS twice for $5 \mathrm{~min}, 0.2 \times \mathrm{SSC}$ twice for $1 \mathrm{~min}$, and $0.1 \times$ SSC twice for $1 \mathrm{~min}$. Slides were dried by centrifugation at $900 \times \boldsymbol{g}$ for 2 min before scanning.

Microarrays were scanned with a scanning laser microscope (ScanArray4000; Packard Bioscience). Separate images were acquired for each fluorochrome at a resolution of $10 \mu \mathrm{m}$ per pixel. To normalize the two channels with respect to signal intensity, photomultiplier and laser power settings were adjusted such that the signal ratio of the control genes was as close to 1.0 as possible. The average fluorescence intensity for each fluorochrome and for each gene was determined by using the QuantArray program Version 3.0 (Packard Bioscience). Background fluorescence was calculated as the median fluorescence signal of non-target pixels around each gene spot. Induction or repression of a gene was defined as a minimum two-fold change in its transcript level. 


\section{Statistical evaluation of microarray data}

Spot intensities (with mean standard deviation) corresponding to the gene of interest in three independent hybridization experiments from three independent tissue samples, are evaluated as the comparison between cocaine-treated (Cy5 labelled samples) and saline-treated (Cy3 labelled samples) using the gene: $\beta$-actin ratios (or gene: GAPDH) ratios. The $P$-values were calculated from variations of densities normalized over each gene by comparison to $\beta$-actin and GAPDH (both of which are unchanged upon cocaine administration) and significance was checked using a $t$-test.

\section{Molecular biology and lentivirus construction}

The CD81 gene (GenBank accession no. NM_013087) was amplified by reverse transcription. Briefly, $2 \mu \mathrm{g}$ of total RNA (prepared from rat nucleus accumbens of cocaine-treated animals) were added to $1 \mu \mathrm{g}$ oligo- $(\mathrm{dT})_{12-18}, 2 \mu \mathrm{L}$ of dNTP mix at $10 \mathrm{mM}$ each and made up to $12 \mu \mathrm{L}$ with RNase free-water. These components were mixed and heated at $65{ }^{\circ} \mathrm{C}$ for $5 \mathrm{~min}$ then kept on ice. Four microlitres of $5 \times$ first strand buffer were added to the mixture, followed by $2 \mu \mathrm{L} 0.1 \mathrm{M}$ dithiothreitol, $10 \mathrm{U}$ RNAsin (Invitrogen \#15518-012), $1 \mu \mathrm{L} 200 \mathrm{U} /$ $\mu \mathrm{L}$ Superscript II RNaseH-reverse transcriptase (Invitrogen \#18064014). The mixture was incubated at $42{ }^{\circ} \mathrm{C}$ for $3 \mathrm{~h}$. To remove RNADNA hybrids, 2 U RNaseH (Invitrogen \#18021-071) were added and incubated at $37^{\circ} \mathrm{C}$ for $30 \mathrm{~min}$. The cDNA was then PCR amplified and 6 His-tagged with the following two primers: CGCGGATCCGCGATGGGGTGGAGGGCTGC as forward primer and CCGCTCGAGCGGTTAATGATGATGATGATGATGGTACACGGAGCTGTTCCGG as reverse primer. The forward primer contains a BamHI restriction site followed by the $5^{\prime}$ rat CD81 cDNA specific sequence, the reverse primer contains the $3^{\prime}$ rat CD81 cDNA specific sequence, a 6His-Tag, a stop codon and an XhoI restriction site.

The PCR product was digested with BamHI and XhoI and cloned into similar sites in pTK431 (Fig. 2). The pTK431 is a self-inactivating (SIN) HIV-1 vector, which contains the entire tet-off inducible system, the cPPT and the woodchuck hepatitis virus post-transcriptional regulatory element (WPRE). It was generated by ligating a BglII/BamHI DNA fragment containing the tetracycline-regulated transactivator tTA $\left(5^{\prime}\right)$ and the tetracycline inducible promoter $\left(3^{\prime}\right)$ into a BamHI site downstream to a CMV promoter in a SIN HIV-1 vector. A control vector construct, pTK433, in which GFP expression is regulated by a tetracycline inducible promoter, was generated by cloning a $B a m \mathrm{HI} / B g 1$ II DNA fragment containing the GFP gene into a BamHI site in pTK431 (Fig. 2). All plasmids were $\mathrm{CsCl}_{2}$ purified.

The vector plasmid (either pTK431-CD81-6His or pTK433), together with the packaging construct plasmid $\mathrm{p} \Delta \mathrm{NRF}$ and the envelope plasmid pMDG-VSV-G were cotransfected into HEK293T cells to produce the viral particles (Naldini et al., 1996). Briefly, $3 \mathrm{~h}$ before transfection, the cell medium was changed with fresh DMEM supplemented with $10 \% \mathrm{FCS}, 50 \mathrm{U} / \mathrm{mL}$ penicillin, $50 \mu \mathrm{g} / \mathrm{mL}$ streptomycin, $0.25 \mu \mathrm{g} / \mathrm{mL}$ fungizone and $1 \mathrm{mM} \mathrm{L}$-glutamine. A total of $30 \mu \mathrm{g}$ plasmid DNA was used for the transfection into HEK293T cells at $\approx 50 \%$ confluence, on a 10 -cm-diameter plate precoated with $0.001 \%$ poly lysine (Sigma \#P4707). The DNA was prepared in the following proportions: $15 \mu \mathrm{g}$ of pTK431-CD81-6His (or pTK433GFP), $10 \mu \mathrm{g}$ of the $\mathrm{p} \Delta \mathrm{NRF}$ packaging plasmid and $5 \mu \mathrm{g}$ of the pMDG-VSV-G envelope plasmid. DNA was mixed with $62 \mu \mathrm{L}$ of $2 \mathrm{M} \mathrm{CaCl}_{2}$ and the volume was made up to $500 \mu \mathrm{L}$ with sterile nanopure water. The calcium-DNA mix was added with vortexing to $500 \mu \mathrm{L}$ of $2 \times \mathrm{HBS}\left(280 \mathrm{mM} \mathrm{NaCl}, 10 \mathrm{~mm} \mathrm{KCl}, 1.5 \mathrm{mM} \mathrm{Na}_{2} \mathrm{HPO}_{4}\right.$, $12 \mathrm{mM}$ dextrose 'cell culture grade' and $50 \mathrm{mM}$ HEPES. pH 7.05, adjusted with $0.5 \mathrm{M} \mathrm{NaOH}$, stored at $-20^{\circ} \mathrm{C}$ in $10 \mathrm{~mL}$ aliquots). The mix was incubated for $30 \mathrm{~min}$ at room temperature, vortexed and gently added to the cells. Plates were incubated at $37^{\circ} \mathrm{C}$ with $5 \%$ $\mathrm{CO}_{2}$. Forty-eight hours later, the supernatant was collected, centrifuged $15 \mathrm{~min}$ at $6000 \times \boldsymbol{g}$. A second harvesting was performed after another $48 \mathrm{~h}$. High-titre stocks were obtained by ultracentrifugation at $45000 \times \boldsymbol{g}$ for $2 \mathrm{~h}$ at $4{ }^{\circ} \mathrm{C}$. The pellet was resuspended in PBS buffer containing $1 \%$ bovine serum albumin, and stored frozen at $-80{ }^{\circ} \mathrm{C}$. The viral titres were determined by p24 antigen measurements (KPL, USA). For the in vivo experiments, the different viral stocks matched for viral particle content were used at $0.4 \mathrm{mg} / \mathrm{mL}$ of $\mathrm{p} 24$.

\section{Animal handling and behavioural analysis}

Subjects used in this experiment were male Wistar rats weighing 225$250 \mathrm{~g}$ (BRL, Fillingsdorf, Switzerland). All animal experiments were carried out in accordance with the guidelines and regulations for Animal Experimentation, BAG, Bern, Switzerland. The animals were housed in trios in clear plastic cages with wire grid lids. Access to food and water was unrestricted. Three days after arrival, the first group was maintained with $0.02 \%$ Doxcycycline (Sigma \#D-9891) and 5\% sucrose supplemented in water, the second group in contrast, was maintained only with $5 \%$ sucrose. The animals were kept in the animal facility maintained on a 12-h light:12-h dark cycle (lights off at $19: 00 \mathrm{~h})$.

\section{Stereotaxic surgery and injection of the lentiviral vector}

All animal experiments were carried out in accordance with the guidelines and regulations for Animal Experimentation, BAG, Bern, Switzerland. Before the operation, rats were injected with Domitor $(0.4 \mathrm{mg} / \mathrm{kg}$ medetomidine, s.c.), kept for $15 \mathrm{~min}$ and injected with sublimase (Fentanyl $450 \mu \mathrm{g} / \mathrm{kg}$, i.p.). After $15 \mathrm{~min}$, the surgical field was shaved, cleaned using hibitane solution $(0.5 \%$ chlorhexidine gluconate in $70 \%$ ethanol) and lacrilube was applied to eyes.

Animals were placed into a stereotaxic frame (Stoelting, IL). Stereotaxic injections were performed using a $5-\mu \mathrm{L}$ Hamilton syringe with a 33-gauge tip needle. The injections were performed in the VTA (anterior -6 ; lateral \pm 0.5 ; ventral -8.2 ) and the NAcc (anterior +1.4 ; lateral \pm 1.6 ; ventral -6.8 ) as calculated from bregma and the dura mera. The skin was opened with a scalpel incision along the midline and $0.2 \mathrm{~mL}$ of Mercain $(0.25 \%$ bupivacaine hydrochloride) was applied to the wound for local analgesia. Overlying tissue was blunt dissected with sterile Q-tips to visualize bregma and the skull was delicately bored at predetermined coordinates. Heating of the skull is reduced by application of sterile $0.09 \%$ saline solution around the drilling site. Male Wistar rats were bilaterally injected into the VTA or into the NAcc with $4 \mu \mathrm{L}$ of concentrated lentiviral stock (co-injection of $2 \mu \mathrm{L}$ of lenti-CD81His 6 together with $2 \mu \mathrm{L}$ of lenti-GFP) slowly infused at the speed of $\sim 0.2 \mu \mathrm{L} / \mathrm{min}$. The cannula was then maintained in place for a further 5 min after injection and then withdrawn very slowly to prevent backflow of solution. The wound site was closed with braided silk suture. Rats were then removed from the frame, injected with a mixture of Antisedan (atipamezole $1 \mathrm{mg} / \mathrm{kg}$, s.c.) and Nubain (nalbuphine $2 \mathrm{mg} / \mathrm{kg}$, s.c.) for reversal, $2.5 \mathrm{~mL}$ of $0.09 \%$ saline solution and Rimadyl (carprofen $2 \mathrm{mg} / \mathrm{kg}$, s.c.) for hydratation and pain relief. Lacrilube was re-applied to eyes. The animal was returned back to the cage out of the surgery room, kept warm and off sawdust (as this can be inhaled by rats not fully conscious). The post-op diet for 3 days consisted of normal food pellets soaked in water with $0.02 \%$ Doxcycycline for the first group and without Doxycycline for the second one. Rat recovery was followed up. 

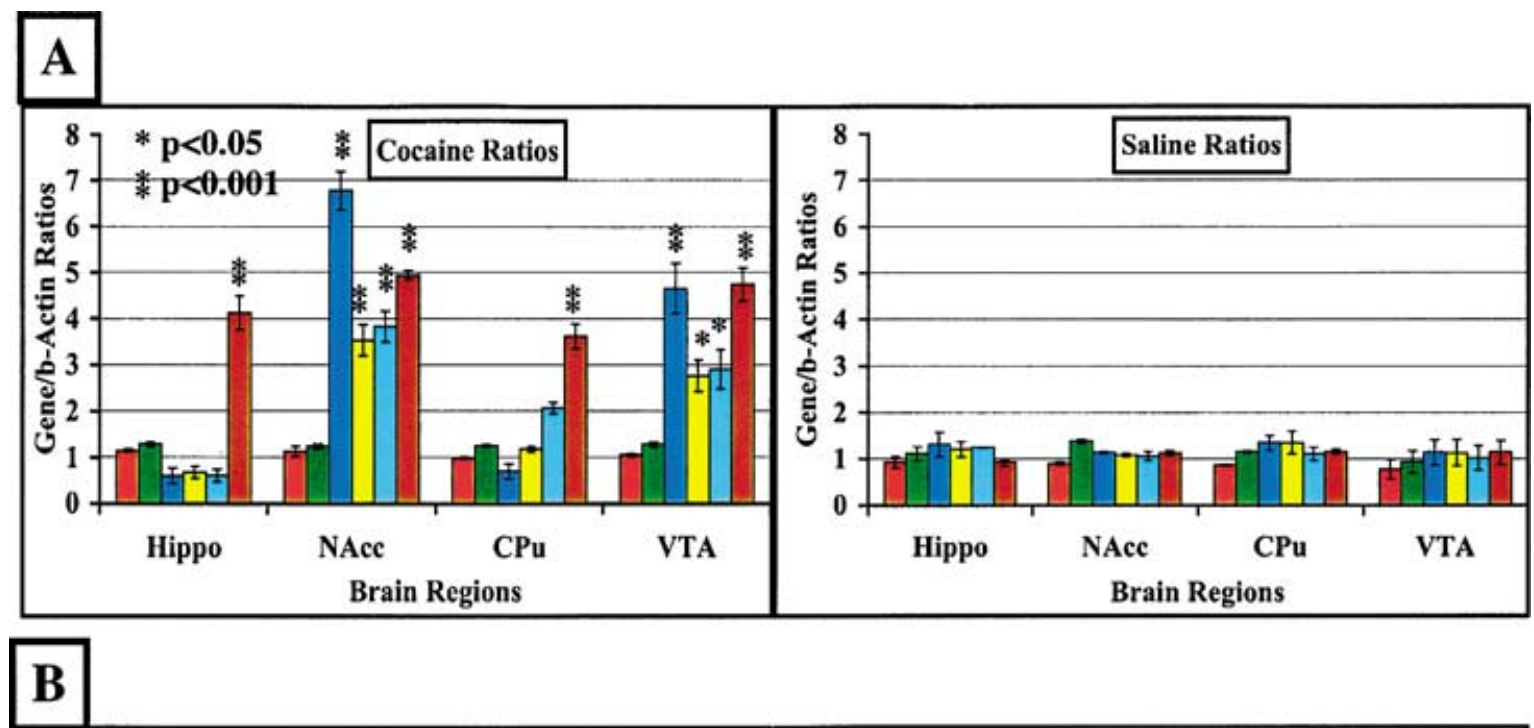

B
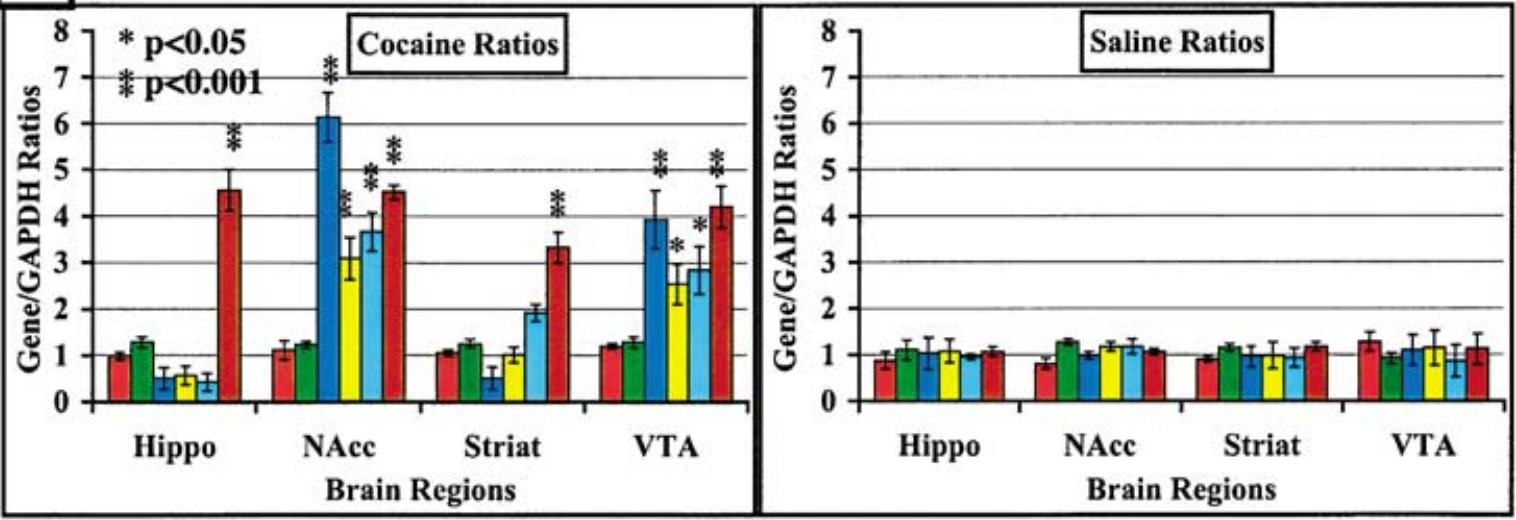

\section{3-Actin $\square$ GAPDH $\square$ CD81 $\square$ CD9 $\square$ r-galanin $\square$ CART}

FIG. 1. Microarray analysis of CD81 expression changes in the hippocampus, nucleus accumbens, striatum and ventral tegmental area of cocaine-treated/untreated rat brains. Microarrays were prepared as silylated microscope slides, as described in the Materials and methods section, from inserts of cDNA clones. Candidates were amplified and spotted in at least triplicate spots on a glass microarray, together with controls. Controls included 20 candidates from plant and yeast genomes (as negative controls), three different fragments of rat $\beta$-actin and GAPDH (as neutral controls). CART (cocaine-amphetamine regulated transcript) was spotted as a positive control. Total RNA from four different brain areas, including the tegmentum, the NAcc, the hippocampus and the dorsal striatum of cocaine-treated and saline-treated animals were prepared, labelled with Cy5-dCTP (cocaine-treated subjects) and Cy3-dCTP (saline-treated subjects) and hybridized on the microarrays. aRNA preparation and hybridization was performed thrice from three independent series of cocaine or saline-treated animals. Arrays were scanned and analysed as described. Results were normalized and quantified: mean values (with mean standard deviation) from spot intensities corresponding to the same gene from three independent hybridization experiments from three tissue samples, are plotted as cocaine-treated (Gene: $\beta$-actin or Gene: GAPDH from Cy5 labelled samples) vs. saline-treated probes (Gene : $\beta$-actin or Gene : GAPDH from Cy3 labelled samples). (A) Gene : $\beta$-actin ratios for cocaine and for saline probes. (B) Gene : GAPDH ratios for cocaine and for saline probes. For quantification (see Materials and methods section), spot intensities corresponding to the gene of interest are evaluated (with mean standard deviation) as the comparison between cocaine-treated (Cy5-labelled samples) and saline-treated samples (Cy3-labelled samples) using the Gene : $\beta$-actin (A) or Gene : GAPDH ratios (B). The $P$-values were calculated from variations of densities normalized over each gene by comparison to $\beta$-actin and GAPDH (which both are unchanged) and significance was checked using a $t$-test. ${ }^{*} P<0.05$; ${ }^{* *} P<0.001$. Hippo, hippocampus; Nacc, nucleus accumbens; Cpu, caudate putamen; VTA, ventral tegmental area.

FIG. 2. Gene constructs and in vivo expression. (A) Transfer plasmids pTK431-CD81-6His and pTK433-GFP used in this study for the production of lentiCD81-6His and lentiGFP. The plasmids contain a Tet-Off element under the control of a minimal CMV promoter and a cPPT element. (B) Gene expression after in vivo transfer of lentiCD81-6His and lentiGFP. Two microlitres of lentiGFP and lentiCD81-6His $(2 \times 105 \mathrm{ng}$ p24/mL $)$ were mixed and co-injected into the VTA or into the NAcc (coordinates, see Material and methods). Animals were given either 5\% sucrose (-DOXY) or 5\% sucrose : 0.02\% Doxycycline (+DOXY). After 2 weeks, animals were killed, brains removed and processed for immunohistochemistry. GFP expression is monitored directly and CD81-6His is monitored as Texas Red (see Material and methods section). Magnification 40×; right panels, Nissl stains of the injection sites (magnification $2.5 \times$ ). (C) In vivo regulation of gene expression by Doxycycline. LentiCD81-6His and lentiGFP $(2 \mu \mathrm{L}$ each) were stereotaxically co-injected bilaterally into the NAcc (coordinates see Materials and methods) of four groups of animals and the animals were killed, respectively, before giving Doxycycline (no DOXY), or $24 \mathrm{~h}$ (DOXY $24 \mathrm{~h}$ ) or $72 \mathrm{~h}$ (DOXY $72 \mathrm{~h}$ ) after giving Doxycycline (5\% sucrose : $0.02 \%$ Doxycycline, ad libitum in the drinking water). After $72 \mathrm{~h}$ with Doxycycline, Doxycycline was removed from the last group of animals which were killed $96 \mathrm{~h}$ later (no DOXY $96 \mathrm{~h}$ ). After killing, brains were removed, processed for immunocytochemistry and gene expression in the injection sites was quantitatively evaluated. 


\section{A. CONSTRUCTS}

pTK431

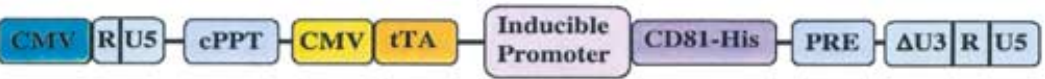

PTK433

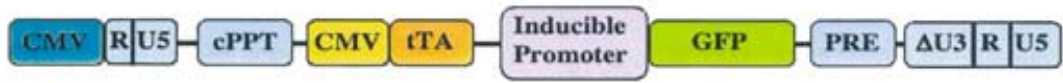

\section{B In vivo GENE EXPRESSION}
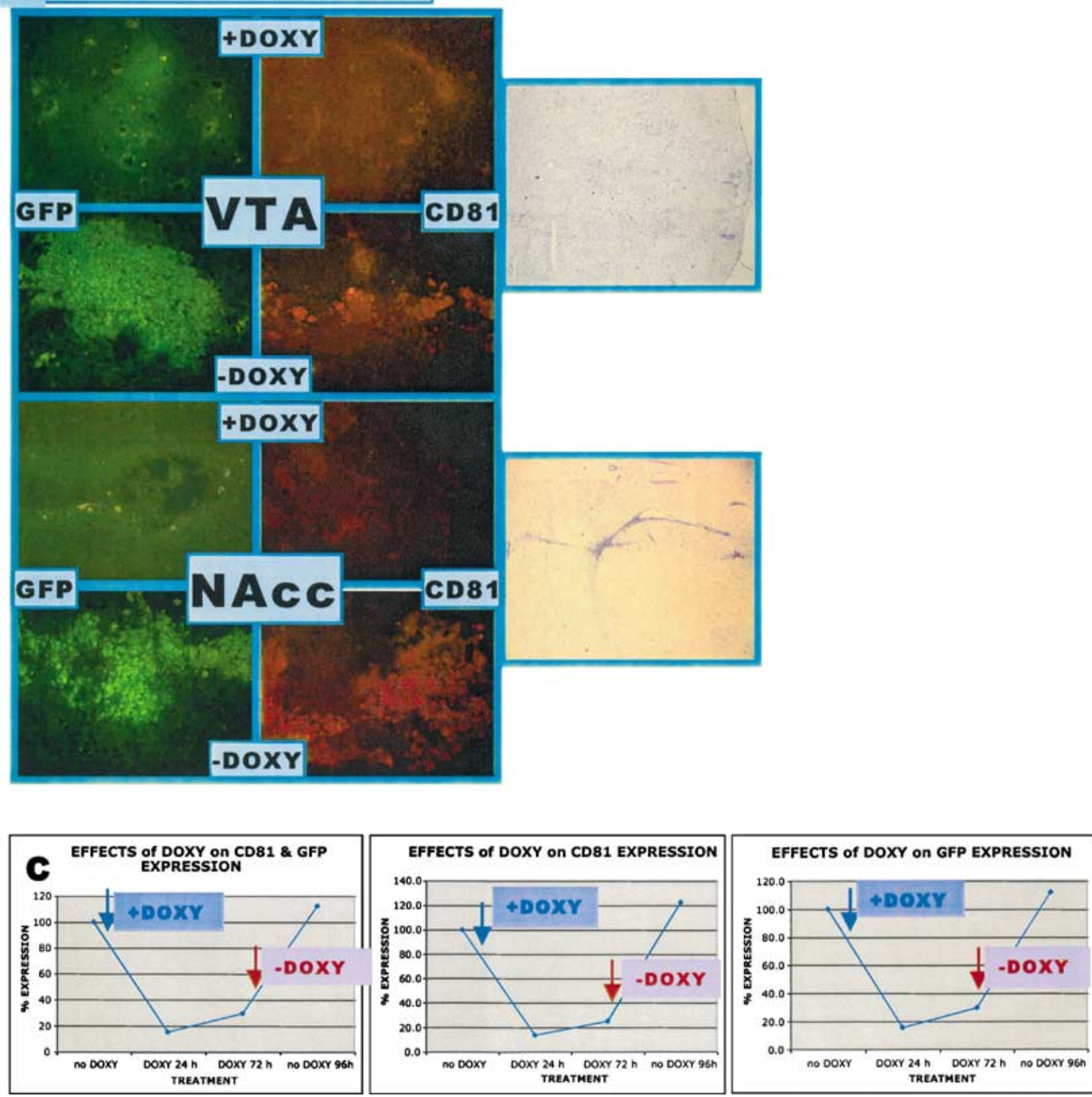


\section{Drug treatment and locomotor activity measurement}

Locomotor activity was monitored during the dark cycle. One week after surgery, each subject was weighed; the animal was brought down from the animal facility and placed immediately into the activitymonitoring cage for a $30 \mathrm{~min}$ baseline without drug. After a 30-min period, the session automatically paused and during this interval, each subject received cocaine- $\mathrm{HCl}(10 \mathrm{mg} / \mathrm{kg}$, i.p. $)$ and was then placed back into the locomotor activity-monitoring cage for $60 \mathrm{~min}$.

Locomotor activity was monitored in MED-OFA-RS cages (MED Associates Inc. USA). Animals were placed in a square $(43.2 \mathrm{~cm} \times$ $43.2 \mathrm{~cm} \times 30.5 \mathrm{~cm}) \mathrm{PVC}$ retainer. Activity in the monitor was recorded by photobeam interruptions. A ring of 16 sensors, spaced $2.54 \mathrm{~cm}$ from each other, measured the ' $\mathrm{X}-\mathrm{Y}$ ' location of the animal four times per second. The activity monitor computed the location of the animal in each of the $\mathrm{X}$ and $\mathrm{Y}$ dimensions as the middle point between the extreme beam interruptions in this dimension. Two sets of strips were used for the ' $\mathrm{X}-\mathrm{Y}$ ' ambulatory data input while a single set was used for the ' $\mathrm{Z}$ ' rearing data.

Speed was estimated by computing the standard deviation of the distances of the data points to their mean within a sliding time window $0.4 \mathrm{~s}$ wide, constructed around each data point in turn. Box size was defined with two photobeams of $\mathrm{X}$ or $\mathrm{Y}$ to be broken before a movement was considered ambulatory. Starting at time 0 , the box was centred on the subject. When the animal moved to the outside of the box, it was considered ambulatory and the box re-centred on the subject. The subject remained ambulatory until it did not leave the last re-centred box in less than the resting delay. The travelled-distance was then calculated. Stereotypic counts were defined as the total number of beam breaks inside the box.

\section{Statistical evaluation of behavioural analysis}

The use of standard deviation is based on the analysis of the coordinates of the path. This is because estimating the speed, measured as travelled distance per min, in a given time point $t i$ depends on measuring the coordinates in two time points (e.g. the difference between the coordinates at times $t i$ and $t i-1$ ).

Within the same group, the means and standard deviations were carried out on measurements performed each day during one session (either over session A or over session B). No significant changes were observed in day to day recordings over the same session. The means and the standard deviations from all measurements within one session were then calculated (using values obtained from subjects of the same group at the same session) and plotted.

The $t$-test was performed by comparison of the six subjects (three from each group) in the same time point and the $P$-value was calculated to check for the significance of the difference between the groups with and without Doxcycycline.

\section{Immunohistochemistry}

At the end of the session, animals were killed by decapitation. Rat brains were rapidly dissected out and frozen in isopentane upon extraction (at $-30^{\circ} \mathrm{C}$ for $3 \mathrm{~min}$ ) and kept at $-25^{\circ} \mathrm{C}$. Coronal sections were cut at $14 \mu \mathrm{m}$ in a cryostat (Leitz) and placed on gelatinized glass slides, air-dried at room temperature for $20 \mathrm{~min}$ and kept at $-25^{\circ} \mathrm{C}$ until further processing.

Alternate slices were either directly mounted, for observing direct GFP-fluorescence, or labelled with mouse histidine tag antibody (MCA1396, Serotec) for observing CD81-6His expression. In the latter case, sections were fixed in 4\% PFA for $15 \mathrm{~min}$ and then washed three times in PBS. Sections were blocked against non-specific binding for $30 \mathrm{~min}$ at room temperature in $1 \times$ PBS containing $1 \%$ bovine serum albumin, $1 \%$ Triton $\mathrm{X}-100$ and $3 \%$ normal goat serum. Sections were then rinsed and incubated for $90 \mathrm{~min}$ with primary antibody (mouse antihistidine tag antibody, MCA1396, Serotec $1: 6000$ ). Antibody was diluted in $1 \times$ PBS containing $0.01 \%$ Triton X-100 and $1 \%$ normal goat serum. Sections were then washed three times in $1 \times$ PBS and incubated with the secondary antibody (Texas red-conjugated goat antimouse immunoglobulin G, Molecular Probes, $1: 200$ ) in the dark for $45 \mathrm{~min}$ at room temperature. Sections were rinsed three times for $5 \mathrm{~min}$ in $1 \times \mathrm{PBS}$ at room temperature and coverslipped with a medium containing glycerol in $1 \times$ PBS (AF1 mounting solution, Citifluor-Ltd). In all cases negative controls included omission or substitution of the primary antibody.

\section{Fluorescence microscopy}

Stained sections were observed using a multifluorescence microscope (Axioplan 2 imaging; Zeiss) with a $\times 40$ or a $\times 63$ objective and photographed using a multichannel camera (Axiocam, Zeiss) combined to acquisition software (Axiovision system 3.1). The fluorophores (GFP, Texas Red) were detected with the appropriate detecting systems (HAL 100). GFP was excited by a $495 \mathrm{~nm}$ beam and was detected through a light path ranging from 510 to $550 \mathrm{~nm}$. Texas red was exited by a $595 \mathrm{~nm}$ beam and was detected through a light path ranging from 600 to $660 \mathrm{~nm}$.

\section{Quantification}

Sections were photographed with a $\times 40$ objective using a digital camera (Axiocam, Zeiss) attached to a multifluorescence microscope (Axioplan2 imaging, Zeiss). Special care was taken to place the frame in the same location on each region analysed for each animal. Within each section, frame size was kept constant from slide to slide. The density of GFP or CD81-positive cells was calculated for each brain region of interest of each group of six rats, using the Scion software. Each image was transformed into TIFF format, normalized by subtracting the background. Then a semi-automatic cellular density measurement was undertaken by calculating total pixel density at a fixed brightness level. Separate exposures were made for each section to ensure that density measurements were reproducible. The high mean level of pixel intensity correlated to high amounts of expression of either GFP or CD81 in the specific area. To each set of GFP or CD81 immunoreactivity measurements, ANOVA followed by a Scheffe $F$-tests was used. All results are expressed as a mean \pm SEM.

\section{Results}

\section{CD81 up-regulation in NACC and VTA}

CD81 up-regulation in NAcc was initially observed in a differential display screening for genes regulated by cocaine treatment (Michna et al., 2001). The message was present neither in NAcc of salinetreated animals nor in lateral striatum at any condition. A slight expression in the hippocampus of saline-treated animals was also observed. Real-time PCR confirmed CD81 up-regulation after acute cocaine treatment, showing a 4.6-fold increase in the NAcc (Michna et al., 1999; Brenz-Verca et al., 2001; Michna et al., 2001). In the present study, microarrays were prepared to further confirm this upregulation in different paradigms of drug administration. A microarray membrane was prepared bearing CD81, galanin and CD9 together with a variety of control genes [plant and yeast genes as negative controls, CART (cocaine and amphetamine regulated transcript) as positive, cocaine regulated control gene, together with $\beta$-actin and GAPDH as general control genes]. Galanin was spotted because our previous studies have shown that in hypothalamic regions, CD81 is mainly 


\section{Group 1}

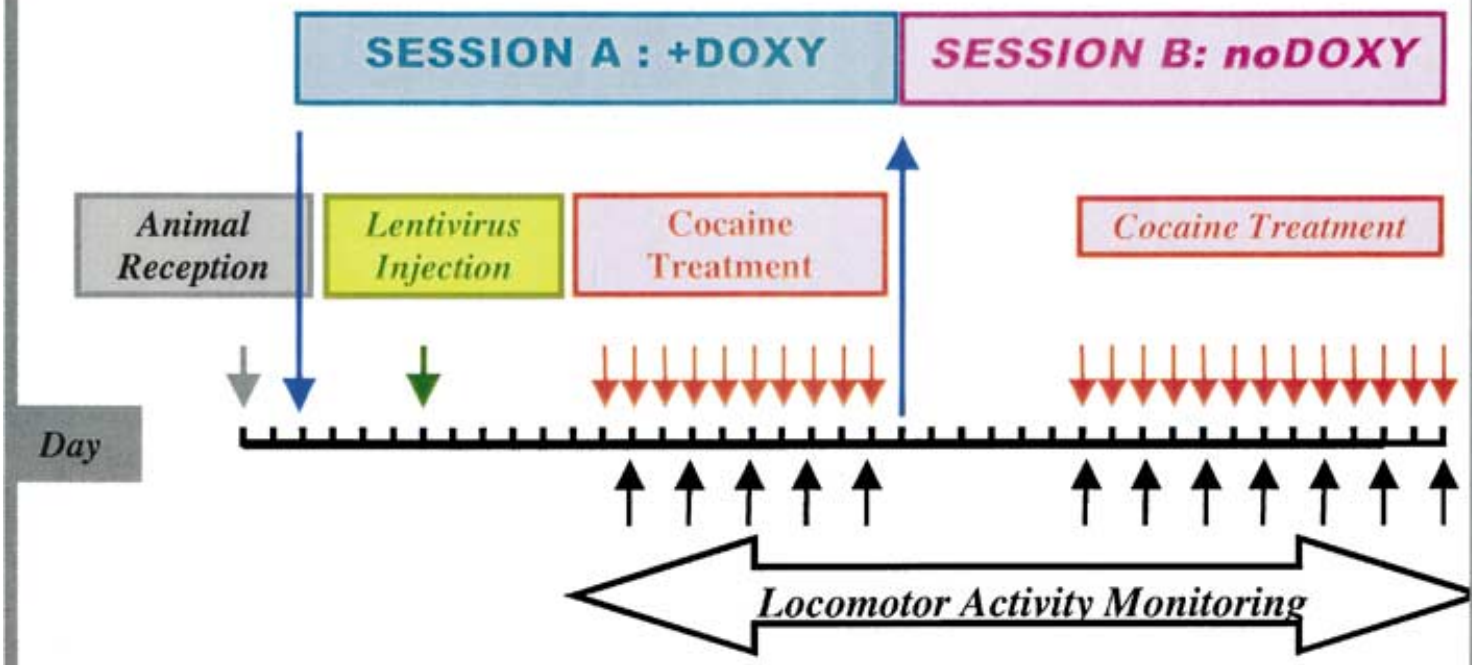

\section{Group 2}

\section{SESSION A : nO DOXY SESSION B : + DOXY}

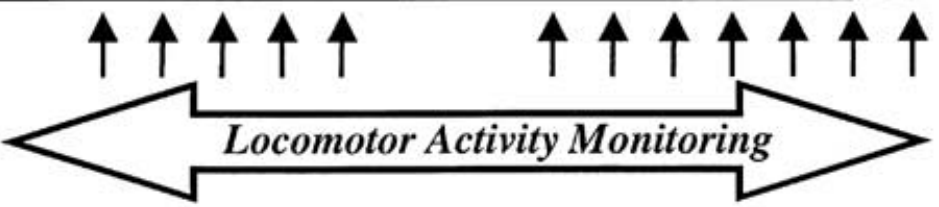

FIG. 3. Drug administration protocol. Upon receipt, animals were divided into two groups (Group 1 and Group 2). Group 1 was given Doxycycline : sucrose in the drinking water at day 4; Group 2 was given only sucrose. At day 7, animals were subjected to bilateral injection of $4 \mu \mathrm{L}$ of lentiCD81/LentiGFP and allowed to recover for another 7 days. Then Session A was initiated with both groups. Each group was administered cocaine daily (10 mg/kg, i.p.) over 10 consecutive days and locomotor activity was measured. At the end of Session A, drug administration was interrupted and the groups were switched. Group 1 was given only sucrose, whereas Group 2 received Doxycycline : sucrose. Seven days after this change, while maintaining this regimen, cocaine administration (same doses) was continued daily over 12 consecutive days (Session B) and locomotor activity monitored. Thus each group has received the same drug treatment, but under opposite conditions of Doxycycline administration. At the end of the second period, animals were killed, brains removed and prepared for immunohistochemistry. Blue arrow, time point where Doxycycline was administered or removed; red arrows, time points where cocaine was administered; black arrows, time points where measurements were made. 
expressed in pathways associated with galanin (Brenz-Verca et al., 2001). CD9 is described as being associated to the tetraspanin CD81 and important for its physiological function and signalling. RNA from four regions NAcc, VTA, CPu and hippocampus of naïve or cocainetreated rats ( $n=6$ per group) were pooled, amplified and labelled with $\mathrm{Cy} 3$ or $\mathrm{Cy} 5$ and the product was hybridized on the microarrays. As shown in Fig. 1, CD81 is up-regulated together with galanin and CD9, both in the VTA and in the NAcc. Cocaine induced a 2.5 -fold increase in CD81 mRNA expression in the VTA and a four-fold increase in the NAcc, in agreement with our previous data, based on real-time PCR differential display and immunohistochemistry (Brenz-Verca et al., 2001; Michna et al., 2001). The up-regulation was not observed in other brain regions tested, e.g. the hippocampus and the $\mathrm{CPu}$, where rather a 1.8-fold down-regulation was observed. $\beta$-actin and GAPDH, used as controls, show no change in expression in all regions tested. Importantly, in agreement with earlier studies (Couceyro et al., 1998; Fagergren \& Hurd, 1999) we observed a significant increase in CART expression in the four brain regions. These data strongly confirm previous reports and clearly indicate that CD81 up-regulation is specific for certain brain regions and that CD81 may play a major role in the response to cocaine.

\section{Regulatable lentivirus}

In order to test the effects of CD81 in vivo, we have developed inducible lentiviral vectors, which allowed regulated transgene expression in vivo. As shown in Fig. $2 \mathrm{~A}$, the vectors contain a constitutive expression cassette from which the tetracycline transactivator (tTA) is expressed under the control of a CMV promoter and a tetracycline-regulated expression cassette, which controls the expression of either the His-tagged CD81 cDNA or the GFP reporter gene (pTK431-CD81-His6 and pTK433-GFP, respectively). Vector particles were produced by the transient triple plasmid transfection procedure and concentrated by ultracentrifugation. The ability of the vectors to deliver and regulate transgene expression in vitro was confirmed following transduction of HEK293T cells (data not shown). To evaluate the ability of the newly developed vectors to regulate transgene expression in vivo, $2 \mu \mathrm{L}$ of concentrated lentiCD81-6His and lenti-GFP-pTK433 particles $\left(0.4 \mathrm{mg} \mathrm{p} 24^{\mathrm{gag}} / \mathrm{mL}\right)$ were stereotaxically injected into VTA or NAcc. Animals were given either $0.02 \%$ Doxycycline : $5 \%$ sucrose $(n=3)$ or water for 1 week prior to surgery. At 2 weeks post injection the animals were killed and the levels of expression was determined by immunocytochemistry. As shown in Fig. 2B, CD81 or GFP are expressed in vivo in the absence of Doxycycline. The expression in vivo remains very local as the virus is deficient for replication and it is stable and long lasting, being maintained over one month in the injection site (Naldini et al., 1996; Trono, 2000).

When animals receive Doxycycline, the expression of both CD81 and GFP is rapidly down-regulated and the level of CD81 expression on the injection site is decreased within $24 \mathrm{~h}$ to approximately 12 $15 \%$ under standard infectivity conditions used in the present study (Fig. 2B and C). Removing Doxycycline restores the level of CD81 expression to $100-120 \%$ of its initial value (Fig. 2C). Lentivirus infection remains local, and induces neither immune reaction nor neurodegeneration (Fig. 2B). Therefore this vector allows for the rapid switch of local gene expression, and constitutes an ideal tool for behavioural investigation. The limited leakiness of the system, due to the high concentration of viral particles used in this study can be reduced with less virus injected. However in our study this leakiness is negligible, because there is already basal CD81 activity in the brain, which is further induced upon cocaine treatment (Brenz-Verca et al., 2001).

\section{Behavioural changes associated with repeated cocaine administration may involve CD81 expression}

A series of in vivo studies was therefore designed to further test the effects of CD81 on drug administration, as summarized in Fig. 3. Upon receipt the animals were divided into two groups $(n=6)$. Four days after arrival, one group (Group 1) received $0.02 \%$ Doxycycline and 5\% sucrose in the drinking water, the other group (Group 2) received only $5 \%$ sucrose. One week after arrival, the animals underwent stereotaxic surgery and were bilaterally injected with lentivirus preparation. The injection consisted of a mixture of $2 \mu \mathrm{L}$ lentiGFP together with $2 \mu \mathrm{L}$ lentiCD81-6His, at similar p2 $4^{\text {gag }}$ concentrations. One week after operation, a first session of cocaine administration was initiated (designated session A). Cocaine was administered chronically (10 mg/kg, daily as i.p. injection) over 10 days and locomotor activity was monitored immediately after the injection. At the end of session A, drug administration was discontinued and the groups were switched: animals from group 2, which had not received Doxycycline so far, were given $0.02 \%$ Doxycycline and 5\% sucrose, and animals from group 1, which had been given Doxycycline, now received only $5 \%$ sucrose. After 1 week of the novel regimen, drug administration (same doses and same schedule) was started again over 12 consecutive days, while the regimen was maintained.

This complete experimental design was performed twice in two different sets of animals. In one set of animals, the lentiCD81-6His had been injected into the VTA (see data presented Fig. 4), and in the second set, injection was performed into the NAcc (see data presented Fig. 5).

In all cases the local expression of CD81 strongly enhances cocaineinduced locomotion and stereotypy. These behavioural changes are not only dependent upon CD81 overexpression, because cocaine increases locomotor activity both with or without Doxycycline, but these changes are dramatically facilitated by CD81 expression. As shown in these figures, when animal are given Doxycycline, i.e. when CD81 is not expressed in the target area (VTA, Fig. 4 or NAcc, Fig. 5), cocaine administration induces a raise in locomotor activity or stereotypy that returns to baseline around $45 \mathrm{~min}$ after drug injection. However, in the absence of Doxycycline this increase is much more significant and one consistently observes a 3.2-fold raise both in locomotor activity and stereotypy when the gene is expressed in the VTA and a 4.2-fold increase when the gene is expressed in the NAcc. When Doxycycline is

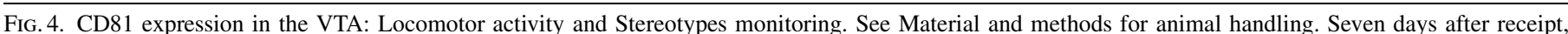

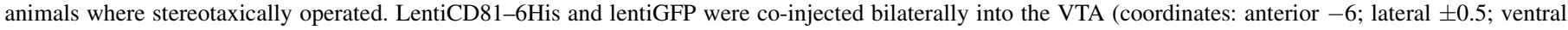

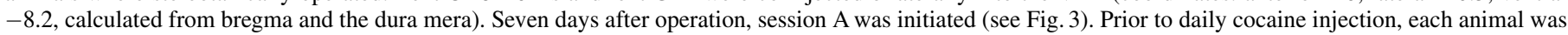

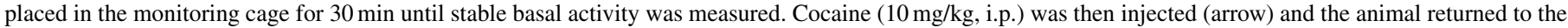

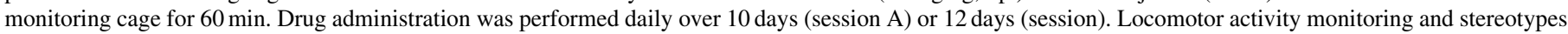

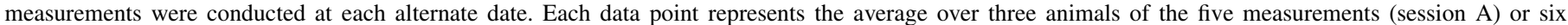

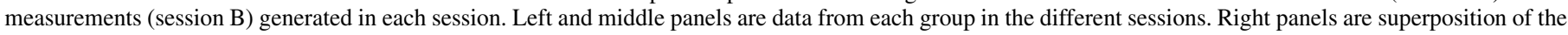

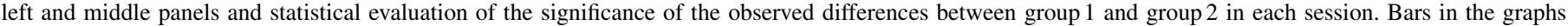
represent means + SEM. ${ }^{*} P<0.05 ;{ }^{* *} P<0.001$. 
CD81 in VTA - LOCOMOTOR ACTIVITY

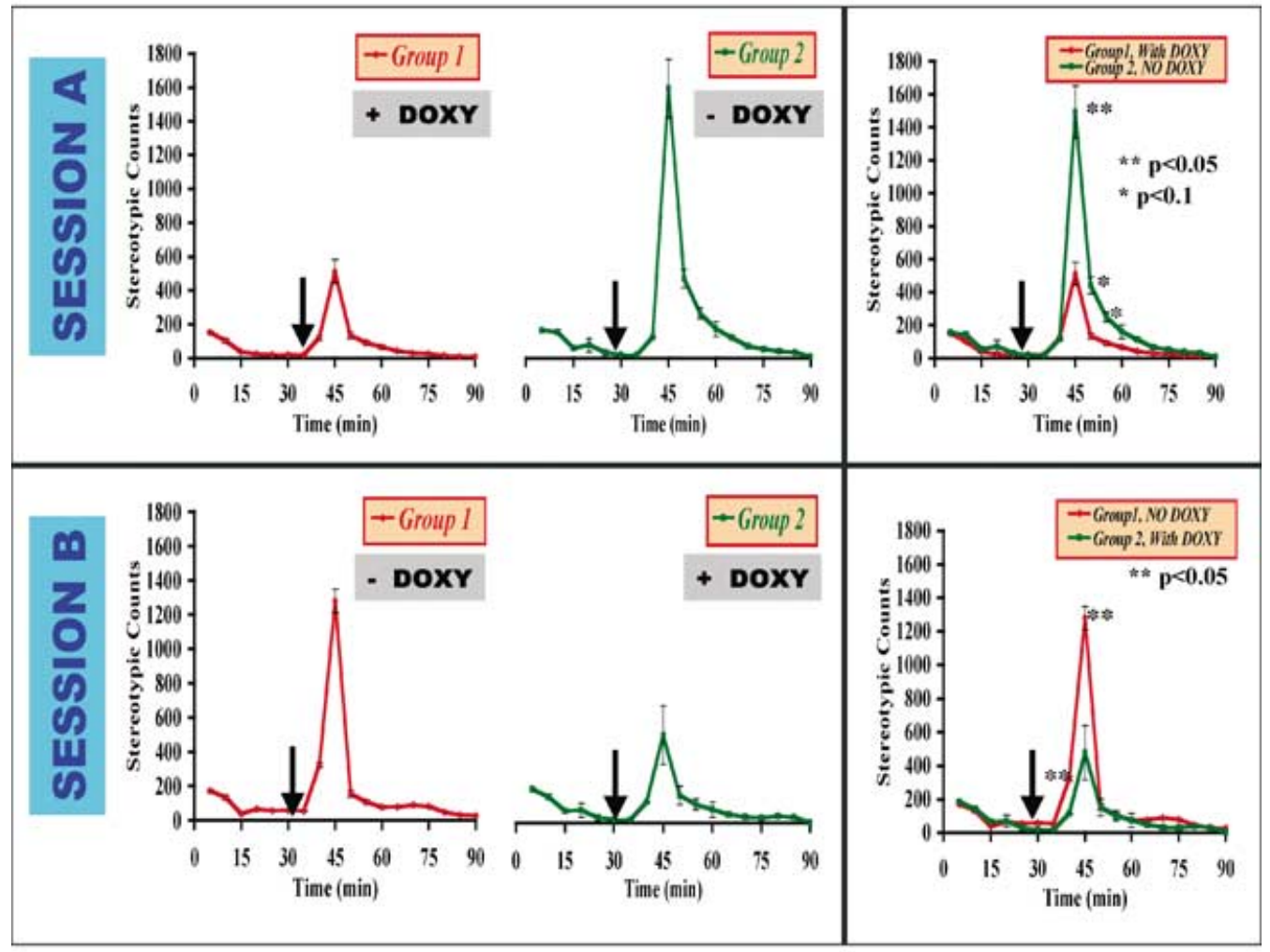

CD81 in VTA - STEREOTYPES

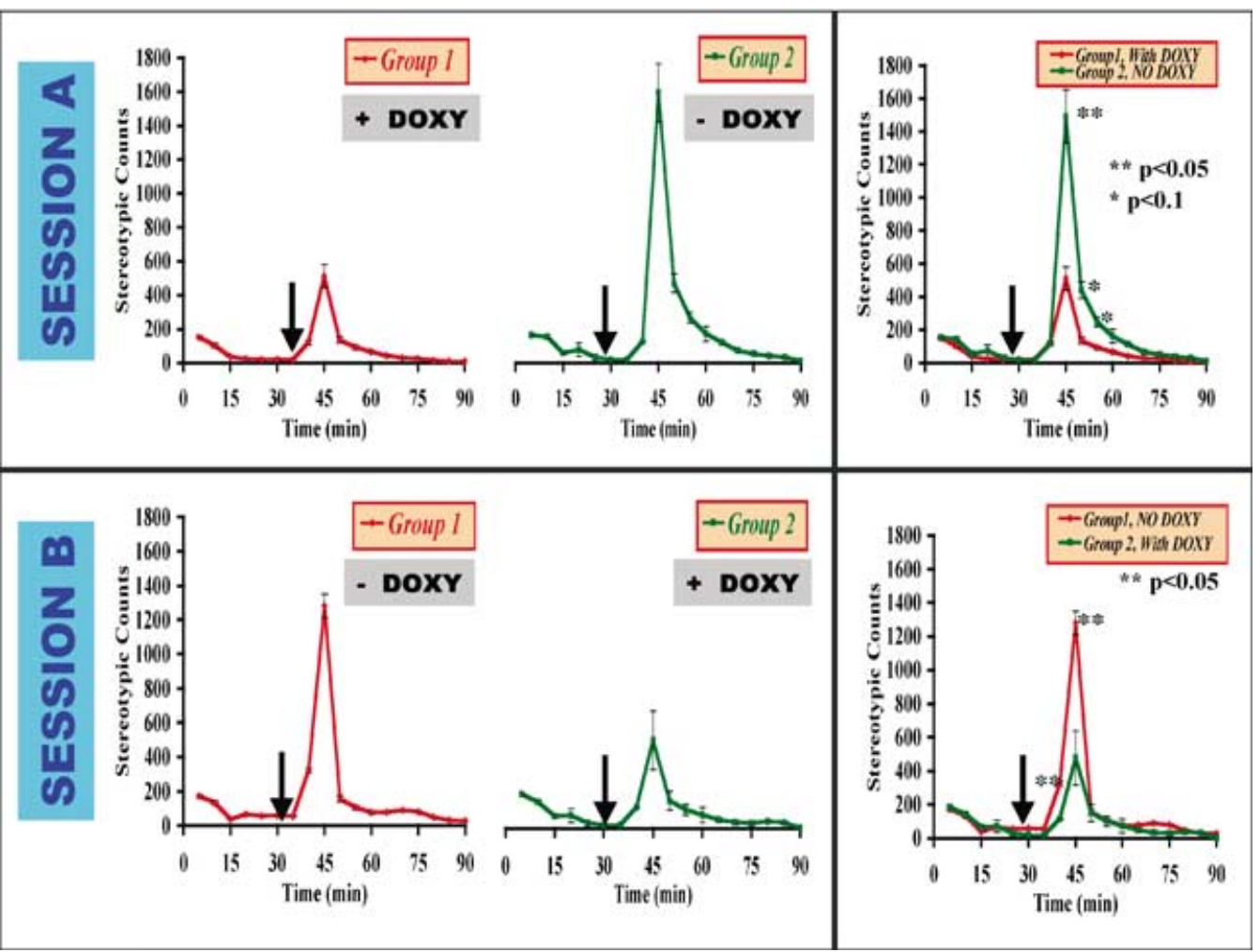




\section{CD81 in NACc - LOCOMOTOR ACTIVITY}

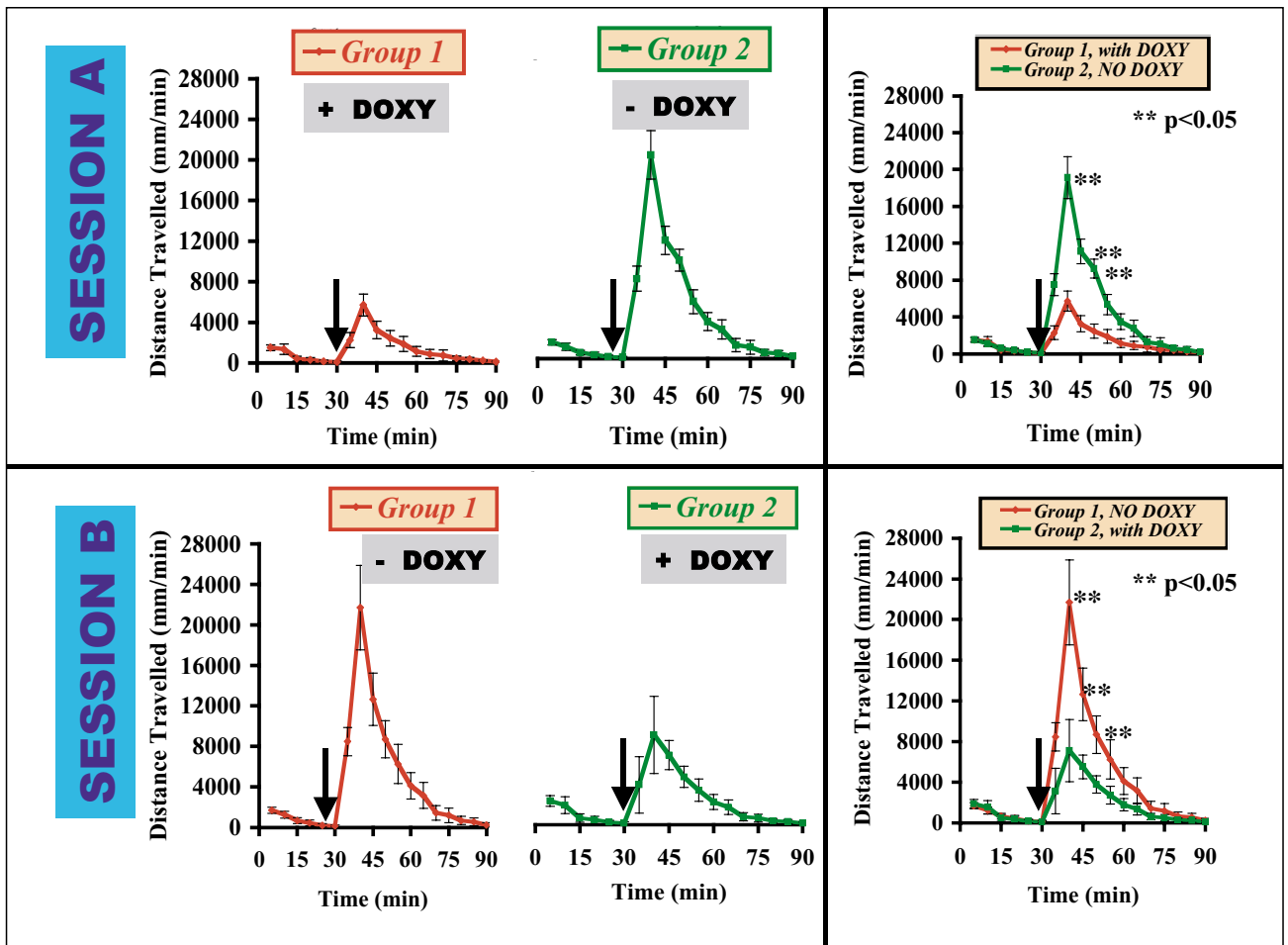

\section{CD81 in NACC - STEREOTYPES}

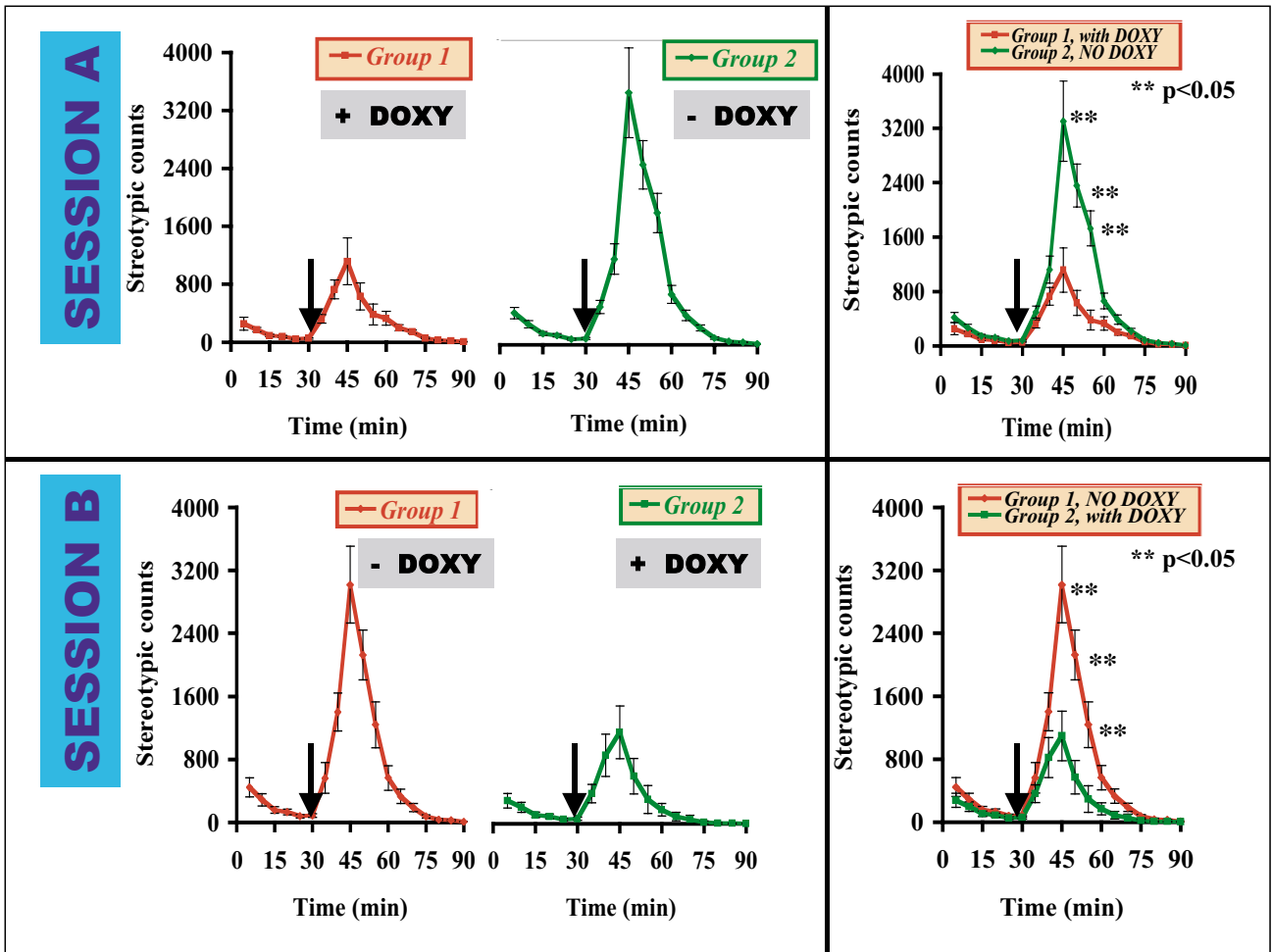

FIG. 5. CD81 expression in the NAcc: locomotor activity and stereotypes monitoring. Same conditions as in Fig. 4, but animals have been operated in the NAcc (bilateral stereotaxic injections at coordinates, anterior +1.4 , lateral \pm 1.6 , ventral -6.8 , calculated from bregma and the dura mera). Arrows, time point $(t=30$ min) when cocaine was injected to the animal. 
given again to the animal, the behavioural pattern returns, thus clearly indicating that CD81 may contribute to behavioural changes associated with repeated cocaine exposure.

When the CD81 was expressed into the NAcc, the behavioural changes were strongly increased, compared to virus injected into the VTA, and were significantly higher (25-30\%; Fig. 6A). The behavioural changes were also consistently longer lasting, as shown from the different curve shapes. Note that microarray data (Fig. 1) and previous studies (Brenz-Verca et al., 2001), although based on very different regimens $(120 \mathrm{mg} / \mathrm{kg}$ over $24 \mathrm{~h}$, compared to $10 \mathrm{mg} /$ day in behavioural studies), consistently displayed higher endogenous expression of CD81 in the NAcc after cocaine. However, the two paradigms are too different to allow further comparison and also the level of expression locally induced by the lentivirus is much higher than drug-induced up-regulation of CD81 under any paradigm.

Patterns displayed in the right-side panels in Figs 4 and 5 represents the overlay of group 1 and 2 from a given session. The average combined from each period and each group in a given condition were evaluated and the effects observed in each group were statistically compared. As shown the changes observed between two groups in a single session are statistically very significant and very reproducible. Within a single session and for any single group, however, we observed no statistical difference over time when any day period taken individually was compared to the whole session under the same conditions

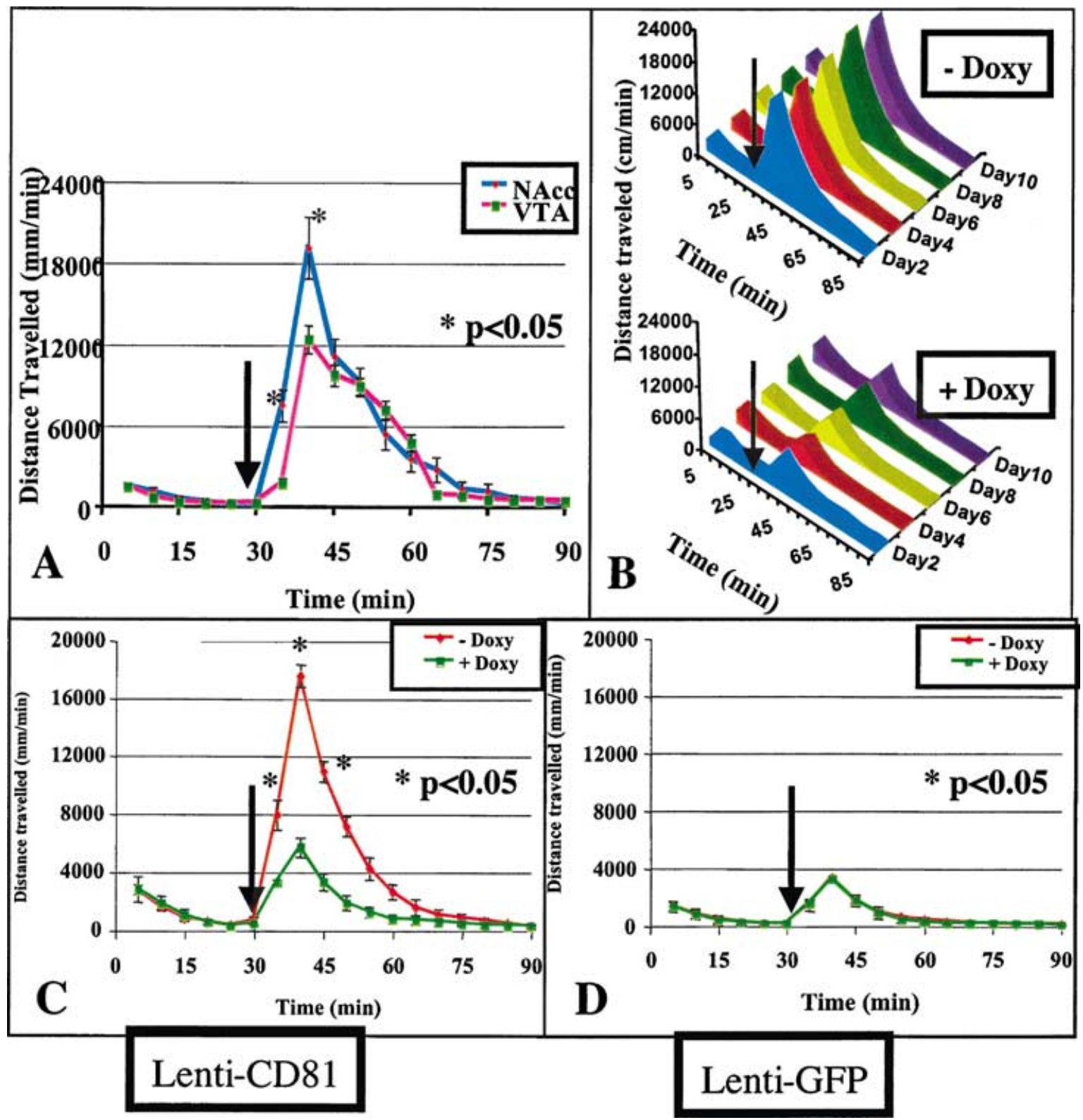

FIG. 6. (A) Comparison of locomotor activity of animals expressing CD81 in the NAcc or in the VTA. Using a $t$-test, the difference between the distance travelled by animals injected in the VTA and animals injected in the NAcc was calculated. The $P$-values $(P<0.05)$ at $t=35$ min and $t=40$ min are highly significant and confirm the finding that behavioural changes were strongly increased (25\% higher) when the CD81 gene was expressed into the NAcc compared to virus injected in the VTA. (B) Development of sensitization. (C and D) Locomotor activity of animals expressing CD81 (C) or GFP (D) in the NAcc. Same conditions as in Figs 4 and 5, but animals have been operated in the NAcc (same coordinates as in Fig. 5) and injected only with lentiCD81-6His (C) or only with lentiGFP (D), respectively. Animals receiving Doxycyline (C) display similar activity to animals receiving the benign control gene GFP with or without Doxycycline (D), but display drastic increased activity in the absence of Doxycycline $(\mathrm{C})$. Arrows, time point $(t=30 \mathrm{~min})$ when cocaine was injected into the animal. 
(Fig. 6B). Thus, once CD81 is expressed (or down-regulated in doxytreated animals) the locomotor activity monitored upon cocaine injection yielded the same amplitude during each of the 10-12 days of a given session and animals did not display an increase or sensitization during a single session over time. As shown in Fig. 6C and D, enhanced behavioural changes and increased locomotor activity is achieved by the overexpression of CD81, and expression of GFP induces no change compared to Doxycycline fed animals.

\section{Discussion}

Drug addiction is a polygenic disorder, implying that changes in expression of a subset of genes is responsible for the onset of the disorder, even when these changes are very local and contribute to less than two per cent each to the disorder. Along these lines, our previous studies identified CD81 as one such gene candidate locally induced in the VTA and NAcc after drug administration under different paradigms. CD81 displays only a 3-4-fold increase from microarray data and previous observations, but this is sufficient for behavioural changes (Michna et al., 2002). Clearly not the only factor involved in this polygenic disorder, it nevertheless may contribute very significantly. To characterize further the effects of CD81, we have developed here a strong system based on the use of an inducible lentivirus system, enabling the role of local changes in expression to be assessed. Our data show that this regulatable lentivirus system is a tool of choice for assessing behavioural changes, because the gene may be transferred very locally, inducing permanent changes of gene expression in the target area, which may then be controlled with Doxycycline. This provides a powerful means by which to verify other data under various paradigms in vivo. It is noteworthy that even a relatively low local increase in gene expression, in our case a 3-4-fold increase in the VTA or in the NAcc, as detected on microarrays, may then be verified with this regulatable lentivirus system in subsequent in vivo studies aimed at assessing behavioural changes in different pardigms. This system conferred a number of additional advantages to the conventional lentivirus system (Trono, 2000): on the one side gene expression remains local and can be controlled to insure lowest basal activity; on the other side rapid response after induction allows genes to be expressed quickly, but only when and where expression is desired. Although in this study we have introduced a relatively long time period of 7 days between on and off sessions, this time period can be considerably reduced ( $24 \mathrm{~h}$ only, Fig. $2 \mathrm{C}$ ). The major advantage of this system lies in the fact that the very same animal can be used as its own control. Behavioural changes, associated with drug sensitization, may be investigated on a single animal under different conditions in a given paradigm and different paradigms can be tested on the same animal. This minimizes bias due to individuals, as demonstrated by the very high reproducibility and statistical significance of the data presented here. Together this also reduces the number of animals needed for statistically significant data analysis. This approach also allows for co-injection with GFP for determining expression efficiencies and separating expressing from non-expressing cells in vivo. Up-regulation of our system is fast (around $24 \mathrm{~h}$ ), precluding time course analysis comparing gene expression and locomotor responses with repeated treatments at short time intervals.

Microarray data from this study confirm our previous reports that CD81 is induced after high doses of cocaine. CD81 is associated with CD9 (Meacker et al., 1997; Stipp et al., 2001; Takeda et al., 2003), which is also up-regulated in our microarray analysis and they form extensive complexes with other transmembrane tetraspanins and integrins. Based on these findings, molecular tools were developed using our regulatable lentivirus system and behavioural assays were conducted under chronic treatment. From our results, behavioural sensitization does not appear to depend upon CD81, but its overexpression may contribute to behavioural changes associated with drug exposure and strongly enhances the expression but not the initiation of behavioural sensitization. Sensitization can be divided into two distinct temporal parts, initiation and expression, which are both temporally and anatomically distinct (Kalivas \& Stewart, 1991; Pierce \& Kalivas, 1997). Other examples have been described in the literature, e.g. PI3-kinase, which is required also for the expression, but not the induction, of behavioural sensitization (Izzo et al., 2002). Our approach, based on overexpression of CD81, tests only the sufficient rather than the necessary condition for sensitization, which would require its down-regulation below control levels. Furthermore, the lentivirus induces locally very high levels of CD81, much higher than other protocols and its full expression level is already reached $24 \mathrm{~h}$ after removal of Doxycycline, thus inducing fast behavioural changes. Further studies, including self-administration paradigms, will be necessary to further elucidate the role of CD81 in the expression of sensitization and to determine whether natural increases in CD81 are paralleled by increases in cocaine-induced locomotion and cocaine intake.

Recent data on CD81 and its association with receptors within specific brain pathways may contribute to clarify its function. CD81 and CD9 associate with FPRP, the prostaglandin $F_{2 \mathrm{a}}$ receptor regulatory protein (Stipp et al., 2001), which may be of importance in terms of the physiological response after drug treatment. Local up-regulation in neural pathways related to prostaglandins and other neuromediators in addiction may be considered. CD81 also stimulates cytokine production in the immune system (Tsitsikov et al., 1997; Maecker, 2003) and similar effects in the brain have been proposed, including changes in neural circuits upon induction of CD81 in the VTA and the NAcc. CD81 is linked to the hypothalamic galanin pathway (BrenzVerca et al., 2001) which is involved in the inhibition of dopamine release from the median eminence (Melander et al., 1986; Nordström et al., 1987) and inhibition of acetylcholine release in the ventral hippocampus (Fisone et al., 1987). CD81 is also associated with melanocortin circuits and is a target of the melanocortin receptor MC4R in arcuate nucleus (Lamar et al., 2003). The activities of neural melanocortin receptors are tightly regulated by ligands secreted by anorexigenic and orexigenic arcuate nucleus neurons (Lamar et al., 2003). CD81 appears to be part of a signalling cascade involving syndecans and mahogany-like proteins that are necessary for normal melanocortin receptor signalling. CD81 is elevated in obese mice with chronic blockade of melanocortinergic signalling due to ectopic expression of agouti signalling protein. This overexpression in obese mice is also observed with increased melanocortin-4-receptor (MC4R) activity and dysfunctions in hypothalamic pathways. Chronic overexpression of MC4R and CD81 appears to form the molecular basis for agouti obesity syndrome, whereas suppression of the gene activity induces obesity in rodents and humans. Elevated expression of CD81 in hypothalamic regions of obese yellow mice thus provides an interesting link between overeating habits and addiction or other reward deficiency syndromes. Related functions in the mesolimbic dopaminergic pathway remain to be established and may contribute to the understanding of the molecular mechanisms involved in drug addiction and related disorders. Further in vivo experiments under different paradigms are necessary to test these hypotheses.

In this study, behavioural changes measured in association with the expression of a specific gene (here CD81) are due to the combination of two effects: first the drug-induced, endogenous overexpression of CD81 in the areas under investigation (VTA or NAcc) and second the expression of CD81 from the lentivirus itself. To prevent the former 
effect, other tools are desired, enabling a complete knock-down of the gene, to minimize the interference and to allow one to distinguish between the two effects.

In conclusion, our study proposes an elegant method for assessing the function of a gene by means of stereotaxic infection of a Doxycycline regulatable lentivirus, allowing for easy switch in local gene expression and for parallel observation of the resulting behavioural changes. These findings clearly confirm our previous studies on a role for CD81 in cocaine-related processes. Here we show that behavioural changes associated with repeated cocaine exposure are affected upon expression of CD81 in the mesolimbic dopaminergic pathway.

\section{Acknowledgements}

Supported by a Swiss National Foundation grant 3100-059350 and 3100AO100686 (J.L.D.) and HIH grant NIDDK RO1 DK58702-03 (T.K.). The authors are also very grateful to Dr George Wagner for critical reading of the manuscript and discussions and to Mrs C. Deforel-Poncet for her skilful technical assistance.

\section{Abbreviations}

$\mathrm{CPu}$, caudate putamen; HEK293T, human embryonic kidney 293T cells; NAcc, nucleus accumbens; SNr, substantia nigra; VTA, ventral tegmental area.

\section{References}

Brenz-Verca, M.S., Brenz-Verca, S., Rusconi, S. \& Dreyer, J.L. (1998) Modification of primer design facilitates the use of differential display. Biotechniques, 24, 378-380.

Brenz-Verca, M.S., Widmer, D.A.J., Wagner, G.C. \& Dreyer, J.L. (2001) Cocaine-induced expression of the tetraspanin CD81 and its relation to hypothalamic function. Mol. Cell. Neurosci., 17, 303-316.

Couceyro, P.R., Paquet, M., Koylu, E., Kuhar, M.J. \& Smith, Y. (1998) Cocaineand amphetamine-regulated transcript (CART) peptide immunoreactivity in myenteric plexus neurons of the rat ileum and co-localization with choline acetyltransferase. Synapse, 30, 1-8.

Fagergren, P. \& Hurd, Y.L. (1999) Mesolimbic gender differences in peptide CART mRNA expression: effects of cocaine. Neuroreport, 10, 3449-3452.

Fisone, G., Wu, C.F., Consolo, S., Nordstrom, O., Brynne, N., Bartfai, T., Melander, T. \& Hokfelt, T. (1987) Galanin inhibits acetylcholine release in the ventral hippocampus of the rat: histochemical, autoradiographic, in vivo, and in vitro studies. Proc. Natl Acad. Sci. USA, 84, 7339-7343.

Geisert, E.E. Jr, Yang, L. \& Irwin, M.H. (1996) Astrocyte growth, reactivity, and the target of the antiproliferative antibody, TAPA. J. Neurosci., 16, $5478-5487$.

Hemler, M.E. (2001) Specific tetraspanin functions. J. Cell Biol., 155, $1103-1108$.

Irwin, M.H. \& Geisert, E.E. Jr (1993) The upregulation of a glial cell surface antigen at the astrocytic scar in the rat. Neurosci. Lett., 154, 57-60.

Izzo, E., Martin-Fardon, R., Koob, G.F., Weiss, F. \& Sanna, P.P. (2002) Neural plasticity and addiction: PI3-kinase and cocaine behavioral sensitization. Nature Neurosci., 5, 1263-1264.

Kacharmina, J.E., Crino, P.B., Eberwine, J. (1999) Preparation of cDNA from single cells and subcellular regions. Methods Enzymol., 303, 3-18.
Kalivas, P.W. \& Stewart, J. (1991) Dopamine transmission in the initiation and expression of drug- and stress-induced sensitization of motor activity. Brain Res. Brain Res. Rev., 16, 223-244.

Lamar, C.R., Gardner, W., Brazda, A. \& Kesterson, R.A. (2003) Putative targets of CNS melanocortin receptor activity. Ann. N.Y. Acad. Sci., 994, 211-217.

Levy, S., Todd, S.C. \& Maecker, H.T. (1998) CD81 (TAPA-1): a molecule involved in signal transduction and cell adhesion in the immune system. Anпu. Rev. Immunol., 16, 89-109.

Maecker, H.T. (2003) Human CD81 directly enhances Th1 and Th2 cell activation, but preferentially induces proliferation of Th2 cells upon longterm stimulation. MBC Immunol., 4, 1-8.

Maecker, H.T., Todd, S.C. \& Levy, S. (1997) The tetraspanin superfamily: molecular facilitators. [Review]. FASEB J., 11, 428-442.

Melander, T., Hokfelt, T., Rokaeus, A., Cuello, A.C., Oertel, W.H., Verhofstad, A. \& Goldstein, M. (1986) Coexistence of galanin-like immunoreactivity with catecholamines, 5-hydroxytryptamine, GABA and neuropeptides in the rat CNS. J. Neurosci., 6, 3640-3654.

Michna, L., Brenz-Verca, M.S., Chen, S., Lee, J., Rogrove, J., Zhou, R., Tsitsikov, E., Miescher, G.C., Dreyer, J.L. \& Wagner, G.C. (1999) Cocaine-induced place preference and activity in CD81-deficient mice. Soc. Neurosci. Abstr., 25, 1793.

Michna, L., Brenz-Verca, M.S., Dreyer, J.L. \& Wagner, G.C. (2002) Methods to examine molecular changes and behavioral effects of drug administration. Brain Res. Protocols, 9, 181-196.

Michna, L., Brenz-Verca, M.S., Widmer, D.A.J., Chen, S.L., Rogrove, J., Zhou, R., Tsitsikov, E., Miescher, G.C.J.-L., Dreyer, J.L. \& Wagner, G.C. (2001) Altered sensitivity of CD81-deficient mice to neurobehavioral effects of cocaine. Mol. Brain Res., 90, 68-74.

Naldini, L., Blomer, U., Gallay, P., Ory, D., Mulligan, R., Gage, F.H., Verma, I.M. \& Trono, D. (1996) In vivo gene delivery and stable transduction of nondividing cells by a lentiviral vector. Science 272, 263-267.

Nestler, E. (2000) Genes and addiction. Nature Genet., 26, 277-281.

Nordström.O., Melander, T., Hokfelt, T., Bartfai, T. \& Goldstein, M. (1987) Evidence for an inhibitory effect of the peptide galanin on dopamine release from the rat median eminence. Neurosci. Lett., 73 (1), 21-26.

Pierce, R.C. \& Kalivas, P.W. (1997) A circuitry model of the expression of behavioral sensitization to amphetamine-like psychostimulants. Brain Res. Brain Res. Rev., 25, 192-216.

Shalon, D., Smith, S.J. \& Brown, P.O. (1996) A DNA microarray system for analyzing complex DNA samples using two-color fluorescent probe hybridization. Genome Res., 6, 639-645.

Stipp, C.S., Kolesnikova, T.V. \& Hemler, M.E. (2001) EWI-2 is a major CD9 and CD81 partner and member of a novel lg protein subfamily. J. Biol. Chem., 276, 40545-40554.

Sullivan, C.D. \& Geisert, E.E. Jr (1998) Expression of rat target of the antiproliferative antibody (TAPA) in the developing brain. J. Comp. Neurol., 396, 366-380.

Takeda, Y., Tachibana, I., Miyado, K., Kobayashi, M., Miyazaki, T., Funakoshi, T., Kimura, H., Yamane, H., Saito, Y., Goto, H., Yoneda, T., Yoshida, M., Kumagai, T., Osaki, T., Hayashi, S., Kawase, I. \& Mekada, E. (2003) Tetraspanins CD9 and CD81 function to prevent the fusion of mononuclear phagocytes. J. Cell Biol., 161, 945-956.

Trono, D. (2000) Lentiviral vectors: turning a deadly foe into a therapeutic agent. Gene Ther, 7, 20-23.

Tsitsikov, E.N., Gutierrez-Ramos, J.C. \& Geha, R.S. (1997) Impaired CD19 expression and signalling, enhanced antibody response to type II T independent antigen and reduction of B-1 cells in CD81-deficient mice. Proc. Natl. Acad. Sci. USA, 94, 10844-10849. 